Ciência Florestal, Santa Maria, v. 22, n. 3, p. 423-431, jul.-set., 2012

ISSN 0103-9954

\title{
SOMBREAMENTO NA EMERGÊNCIA DE PLÂNTULAS E NO CRESCIMENTO INICIAL DE Dipteryx alata Vog.
}

\author{
SHADING IN EMERGENCY OF SEEDLINGS AND ON THE INITIAL \\ GROWTH OF Dipteryx alata Vog.
}

\author{
Leandro Henrique de Sousa Mota ${ }^{1}$ Silvana de Paula Quintão Scalon ${ }^{2}$ Rafael Heinz ${ }^{1}$
}

\section{RESUMO}

Esse trabalho foi desenvolvido com o objetivo de avaliar o potencial de emergência das plântulas e o crescimento das mudas do baru (Dipteryx alata Vog.) em diferentes níveis de sombreamento. Para avaliar a emergência, a semeadura foi realizada em bandejas de células contendo substrato Plantmax ${ }^{\circledR}+$ terra + areia + cama de frango na proporção de 1:1:1:0,5 e mantidas a pleno sol, $50 \%$ e $70 \%$ de sombreamento. O experimento foi realizado em delineamento inteiramente casualizado com três níveis de sombreamento em quatro repetições de 25 sementes. Foram avaliados a porcentagem e o índice de velocidade de emergência. Para avaliar o crescimento inicial, as plântulas foram transplantadas e três repetições de 15 mudas, totalizando 45 mudas, foram mantidas em seus respectivos sombreamentos. O experimento foi realizado em delineamento inteiramente casualizado em esquema fatorial 3 (níveis de sombreamento) x 5 (épocas de avaliação para a altura, diâmetro do coleto, clorofila total, transpiração, condutância estomática e taxa fotossintética) e 2 (épocas de avaliação para área foliar, comprimento de raiz, massas fresca e seca). Os níveis de sombreamento não influenciaram na porcentagem nem no índice de velocidade de emergência das plântulas $(71,3 \%$ e 1,08 , respectivamente). Os maiores valores de altura $(16 \mathrm{~cm})$, área foliar $\left(220,2 \mathrm{~cm}^{2}\right)$, comprimento de raiz $(14,9 \mathrm{~cm})$, massa fresca e seca $(9,71 \mathrm{~g} \mathrm{e} 3,21 \mathrm{~g})$ das mudas foram observados sob sombreamento, não variando entre eles. As mudas apresentaram a menor taxa fotossintética a $70 \%$ de sombreamento $\left(6,8 \mu \mathrm{mol} \mathrm{m}^{-2} \mathrm{~s}^{-1}\right)$. Os níveis de sombreamento avaliados não influenciaram na emergência das plântulas, entretanto, as mudas apresentaram melhor crescimento quando mantidas até os 125 dias de idade sob $50 \%$ de sombreamento.

Palavras-chave: sementes; luz; planta nativa; cerrado; produção de mudas.

\begin{abstract}
This work was carried out in order to evaluate the potential of germination of the seeds and the seedlings growth of baru (Dipteryx alata) in different levels of shading. To evaluate the emergency, the sowing was realized in trays of cells filled with Plantmax ${ }^{\circledR}$ substratum + land + sand + chicken manure in proportion of (1: 1: 1: 0.5 ) and kept in the full sun, $50 \%$ and $70 \%$ of shading. The experiment was carried out in design entirely randomized with three levels of shading in four repetitions of 25 seeds. It was evaluated the percentage and the velocity of the emergency index. To evaluate the initial growth, the seedlings were transplanted and, three repetitions of 15 changes totalizing 45 seedlings were kept in its respective shading. The experiment was realized in a complete randomized design in factorial 3 (shading levels) x 5 (times of evaluation for height, diameter of collect, total chlorophyll, transpiration, stomatal conductance and photosynthetic rate) and 2 (times of evaluation for leaf area, length of root, fresh and dry mass). The shading levels did not influence the percentage and the velocity index of seedling emergency ( $71.3 \%$ and 1.08 respectively). High value of height $(16 \mathrm{~cm})$, leaf area $\left(220.2 \mathrm{~cm}^{2}\right)$, length of root $(14.9 \mathrm{~cm})$, fresh and dry mass $(9.71 \mathrm{~g}$ and $3.21 \mathrm{~g})$ of seedlings were observed under shading not varying between them. The seedlings presented lower photosynthetic rate in the $70 \%$ of shading $\left(6.8 \mu \mathrm{mol} \mathrm{m} \mathrm{m}^{-2} \mathrm{~s}^{-1}\right)$. The levels of shadings did not influence in seedling emergency.
\end{abstract}

Keywords: seeds; light; native plant; cerrado; seedlings production.

1. Engenheiro Agrônomo, Mestrando em Produção Vegetal, Universidade Federal da Grande Dourados, Rodovia Dourados/Itahum, km 12, CEP 79804-970, Dourados (MS). leandromota22@bol.com.br

2. Bióloga, Professora Doutora do Curso de Agronomia, Faculdade de Ciências Agrárias da Universidade Federal da Grande Dourados, Rodovia Dourados/Itahum, km 12, CEP 79804-970, Dourados (MS). silvanascalon@ufgd.edu.br

Recebido para publicação em 19/05/2009 e aceito em 08/06/2011 


\section{INTRODUÇÃO}

O cerrado brasileiro possui a maior diversidade de espécies quando comparado a outras savanas (KLINK e MACHADO, 2005) e tem apresentado grande pressão antrópica, decorrente principalmente da atividade pecuária. No Brasil, a área do Cerrado corresponde a aproximadamente 1,8 milhões de $\mathrm{km}^{2}$ (AGUIAR et al., 2004), $13 \%$ são ocupados com pastagens nativas, $23 \%$ com pastagens cultivadas, $5 \%$ com culturas agrícolas, $18 \%$ com outros tipos de uso e $41 \%$ correspondem às áreas não cultivadas (SANO et al., 2001).

São Paulo, Paraná e Mato Grosso do Sul são os estados que apresentam os menores índices de cobertura vegetal natural $(15,32$ e $32 \%)$, comparados ao Piauí, Maranhão e Tocantins que apresentaram os maiores índices de preservação $(92,89$ e $79 \%$, respectivamente). As áreas de reflorestamento nos Cerrados concentram-se principalmente nos estados de São Paulo, Goiás e Minas Gerais (SANO et al., 2008).

Entretanto, a obtenção de mudas de diversas espécies do ambiente regional em quantidade suficiente para o plantio é um dos principais pontos de estrangulamento dos programas de restauração de determinada área (FONSECA et al., 2001; SANTARELLI, 2004). Isso se deve ao déficit de sementes e à ausência de tecnologia específica para produção de mudas de muitas das espécies nativas (SILVA et al., 2003; ZAMITH e SCARANO, 2004). Uma análise em 30 viveiros florestais do Estado de São Paulo revelou que cerca de 340 espécies arbóreas nativas são produzidas, no entanto, a produção concentra-se em apenas 30 espécies, as quais são as prontamente disponíveis e com tecnologia de produção conhecida e por isso as que predominam nos reflorestamentos (BARBOSA et al., 2003).

O conhecimento sobre a ecofisiologia da germinação e crescimento inicial das mudas é fundamental para o sucesso da atividade de produção de mudas de qualidade, sendo essencial para o sucesso de atividades de reflorestamento e de plantio em florestas naturais. A intensidade luminosa, a temperatura, a concentração de $\mathrm{CO}_{2}$ e a umidade do solo são fatores que afetam a atividade fotossintética e, consequentemente, influem no desenvolvimento das plantas. A sensibilidade das sementes à luz é bastante variável, de acordo com a espécie, havendo sementes cuja germinação é influenciada positivamente ou negativamente pela luz e sementes indiferentes a ela (GONÇALVES et al., 2006).

Dessa forma, modificações nos níveis de luminosidade, as quais uma espécie está adaptada, podem condicionar diferentes respostas fisiológicas em suas características bioquímicas, anatômicas e de crescimento (ATROCH et al., 2001). Como o processo de abertura e fechamento dos estômatos está relacionado principalmente com a intensidade de luz e o estado de hidratação da folha, o funcionamento dos estômatos e a área foliar influenciam na produtividade do vegetal, uma vez que controlam a absorção de $\mathrm{CO}_{2}$ e a interceptação de luz (MARENCO e LOPES, 2005).

Em uma revisão sobre respostas de espécies arbóreas tropicais a diferentes tratamentos de luz em viveiro, Turner (2001) observou que o padrão geral é o maior crescimento das plântulas com o aumento da iluminação até a estabilização a partir de determinada intensidade luminosa, variável entre espécies. A redução na taxa de crescimento é observada principalmente em estudos que incluem um tratamento de luz solar direta.

O sucesso na adaptação de uma espécie em diferentes condições de radiação está relacionado com a eficácia e a rapidez com que os padrões de alocação de biomassa e comportamento fisiológico são ajustados. A maior ou menor plasticidade adaptativa das espécies às diferentes condições de radiação solar depende do ajuste de seu aparelho fotossintético, de modo a garantir maior eficiência na conversão da energia radiante em carboidratos e, consequentemente, maior crescimento (CAMPOS e UCHIDA, 2002).

O baru (Dipteryx alata Vog) - Fabaceae, conhecido regionalmente como pau-cumbaru, frutade-macaco, cumbaru, cumarurana, barujo e cocofeijão, ocorre tipicamente em formações de cerrado e cerradão (MACEDO, 1992). É uma espécie arbórea, que pode alcançar mais de 25 metros de altura em solos muito férteis, tendo uma altura média de 15 metros, sua copa é larga com diâmetro de 6 a 11 metros (SANO et al., 2004), encontrada no Brasil Central, principalmente em Minas Gerais, Goiás, Distrito Federal, Mato Grosso e Mato Grosso do Sul.

O baru é valorizado por suas diversas utilizações, além de ser considerado um grande fixador de nitrogênio no solo, é muito importante pelo seu grande poder alimentício. O fruto é utilizado na forma de farinha, semente in natura, ou torrada, (esta principalmente exportada para o exterior). A casca que sobra do baru é utilizada na 
produção do carvão ecológico (SILVA e EGITO, 2005). Espécie considerada analéptica, diaforética, sudorífica e eficiente no tratamento de distúrbios gastrointestinais. As sementes são também utilizadas para a extração do óleo de baru que é aromático e usado contra dor e reumatismo (CORREA et al., 2000).

Não foram observadas informações na literatura consultada sobre a ecofisiologia das mudas dessa espécie. Objetivou-se com esse trabalho avaliar o potencial de emergência das plântulas e o crescimento inicial das mudas de baru em diferentes níveis de radiação.

\section{MATERIAL E MÉTODOS}

Os frutos de baru foram coletados de diversas matrizes em Dourados no Mato Grosso do Sul, cidade situada a $22^{\circ} 14^{\prime} 16^{\prime \prime} \mathrm{S}$ e $54^{\circ} 48^{\prime} 02^{\prime \prime} \mathrm{W}$ e altitude média de $452 \mathrm{~m}$, com clima classificado como Cwa e a precipitação média anual de 1.500 mm. A temperatura média anual é de $22{ }^{\circ} \mathrm{C}$. O solo, originalmente sob vegetação de cerrado, é de topografia plana e classificado como latossolo vermelho distroférrico de textura argilosa (MATO GROSSO DO SUL, 1990).

O trabalho foi realizado no Laboratório de Fisiologia Vegetal e no Campo Experimental da Faculdade de Ciências Agrárias da Universidade Federal da Grande Dourados-UFGD. A extração das sementes foi realizada abrindo os frutos com o auxílio de uma morsa, descartando as sementes danificadas. As sementes foram submetidas à escarificação química com ácido sulfúrico $\left(\mathrm{H}_{2} \mathrm{SO}_{4}\right)$ por 10 minutos, em seguida foram lavadas em água corrente durante 5 minutos e colocadas para secar à sombra sobre papel toalha por um período de 1 hora.

A semeadura foi realizada em bandejas de isopor com células de 3,0 x 3,0 cm, contendo o substrato Plantmax ${ }^{\circledR}+$ terra + areia + cama de frango semidecomposta, nas proporções de 1:1:1:0,5 $(\mathrm{v}: \mathrm{v})$. Posteriormente à semeadura, as bandejas foram submetidas a três níveis de sombreamento (pleno sol, 50 e $70 \%$ de sombreamento) e irrigadas diariamente, para que não faltasse água para a embebição. Os níveis de 50 e $70 \%$ foram obtidos com auxílio de telas pretas de nylon. Após a emergência das plântulas foram avaliados a porcentagem de plântulas emergidas (\%) e o índice de velocidade de emergência, segundo POPINIGIS (1985). O experimento de emergência foi realizado em delineamento inteiramente casualizado com 3 níveis de sombreamento, contendo quatro repetições de 25 sementes. Aos 25 dias após a emergência (DAE) as plântulas foram transplantadas para sacos de polietileno de $20 \times 12 \mathrm{~cm}$ contendo como substrato terra + areia + cama de aviário, nas proporções em volume de 1:1:1 (v:v) e mantidas em seus respectivos locais de sombreamento, e irrigadas de modo a manter a umidade do substrato em torno de $70 \%$. Aos 45, 65, 85, 105 e 125 dias de idade da muda (DIM) elas foram avaliadas quanto à altura, diâmetro do coleto, clorofila total, transpiração, condutância estomática e taxa fotossintética e aos 45 e 125 dias, a área foliar, comprimento da raiz, massa fresca e massa seca totais. As avaliações de transpiração, condutância estomática e taxa fotossintética foram realizadas entre 9 e 10 horas da manhã, em folhas totalmente expandidas com auxílio do medidor portátil de fotossíntese LCi e a clorofila com SPAD 502.

$\mathrm{O}$ experimento de crescimento inicial foi realizado em delineamento inteiramente casualizado com três repetições de 15 mudas. Os resultados obtidos foram submetidos à análise de variância, e havendo significância, as médias foram comparadas pelo teste de Tukey a $5 \%$ de probabilidade e quando houve interação com as idades das mudas, as médias foram submetidas à análise de regressão. As análises foram realizadas utilizando-se o programa SANEST.

\section{RESULTADOS E DISCUSSÃO}

A porcentagem de plântulas emergidas e o índice de velocidade de emergência não diferiram estatisticamente entre os tratamentos (Tabela 1). Entretanto, a emergência sob $50 \%$ de sombreamento foi $11 \%$ maior e o IVE $29 \%$ maior que a pleno sol.

Observa-se que as plântulas de baru podem emergir sob diferentes disponibilidades de luz, o que representa uma habilidade importante para a espécie, pois propicia uma ampla distribuição, podendo germinar tanto em áreas descobertas, a pleno sol, como nas grandes clareiras ou em sombreamento dos sub-bosques (PORTELA et al., 2001).

Não foi observada interação significativa entre os tratamentos de sombreamento com a idade da muda para as características altura, clorofila total, diâmetro do coleto e transpiração. Avaliando os níveis de sombreamento, a altura das mudas foi maior quando submetidas aos sombreamentos de 50 e $70 \%$ (Tabela 2). 
TABELA 1: Porcentagem de emergência (E) e índice de velocidade de emergência (IVE) de plântulas de Dipteryx alata em função de diferentes níveis de sombreamento.

TABLE 1: Percentage of emergency (E) and index of velocity of emergency (VIE) of Dipteryx alata seedlings in function of levels shadings.

\begin{tabular}{lcc}
\hline Sombreamento & E (\%) & IVE \\
\hline $50 \%$ & $75,00 \mathrm{a}$ & $1,28 \mathrm{a}$ \\
$70 \%$ & $72,22 \mathrm{a}$ & $1,04 \mathrm{a}$ \\
Sol & $66,66 \mathrm{a}$ & $0,91 \mathrm{a}$ \\
CV \% & 13,21 & 14,54 \\
\hline
\end{tabular}

Em que: médias seguidas pela mesma letra nas colunas não diferem entre si pelo teste de Tukey a $5 \%$ de probabilidade.

O sombreamento também induziu maior crescimento em altura de outras espécies como foi observado por Scalon et al. (2003) em Bombacopsis glabra sob $50 \%$ de sombreamento, por Demuner et al. (2004) em Gallesia integrifolia mantidas sob $45 \%$ de sombreamento e por Duz et al. (2004) em Cecropia glazioui submetidas a $50 \%$ de sombreamento.

A capacidade de rápido crescimento em ambiente sombreado é um mecanismo importante de adaptação da espécie, o que constitui uma valiosa estratégia para escapar às condições de baixa disponibilidade de luz (MORAIS-NETO et al., 2000). Nessa condição as plantas tentariam investir maior quantidade de fotoassimilados na parte aérea, além do maior alongamento celular, o que contribuiria para maior altura dessas espécies sob ambientes sombreados. O menor crescimento das mudas quando mantidas a pleno sol, pode ser atribuído a algum processo de fotoinibição (KITAJIMA, 1996). A altura apresentou um crescimento linear, alcançando ao final do experimento valores de 18,55 cm (Figura 1a).

O diâmetro do coleto mostrou-se indiferente aos níveis de luminosidade avaliados (Tabela 2), e um aumento quadrático ao longo das avaliações, apresentando ao final do experimento $5,11 \mathrm{~mm}$ (Figura 1b). Esse comportamento do diâmetro das mudas, associado aos resultados observados para a germinação, reforça a ideia de que o baru é uma espécie tolerante a um amplo espectro de radiação nessa fase inicial do desenvolvimento.

Observa-se na literatura que existe uma alta correlação entre o diâmetro e altura do coleto e a sobrevivência das mudas depois do plantio, o que faz deste parâmetro um aspecto de extrema importância. Observa-se também que em níveis de sombreamento mais elevados, há uma diminuição dos fotoassimilados e de reguladores de crescimento, em razão da diminuição da fotossíntese, o que reflete no menor desenvolvimento em espessura do caule (LARCHER, 2000; TAIZ e ZEIGER, 2004). Essa estreita relação entre fotossíntese e o crescimento do diâmetro do coleto foi observada por Atroch et al. (2001), que verificaram uma dependência de maiores quantidades de carboidratos acumulados e um balanço favorável entre fotossíntese líquida e respiração para a ocorrência de acréscimos no diâmetro do coleto.

As respostas das plantas às condições de sombreamento são consequência da plasticidade adaptativa de cada espécie, sendo estas variáveis dependentes do habitat que a espécie ocupa. Scalon et al. (2003 e 2008) avaliando o crescimento inicial

TABELA 2: Altura (A), diâmetro do coleto (D), clorofila total (CT) e transpiração (E) de mudas de Dipteryx alata em função dos níveis de sombreamento.

TABLE 2: Height (H), diameter of collect (D), total chlorophyll (TC), transpiration (E) of seedlings of Dipteryx alata in function of levels shading.

\begin{tabular}{ccccc}
\hline \multirow{2}{*}{ Sombreamento } & $\mathrm{A}$ & $\mathrm{D}$ & $\mathrm{CT}$ & $\mathrm{E}$ \\
\cline { 2 - 5 } & $(\mathrm{cm})$ & $(\mathrm{mm})$ & $\left(\mu \mathrm{g} \mathrm{cm}^{-2}\right)$ & $\left(\mathrm{mmol} \mathrm{m}^{-2} \mathrm{~s}^{-1}\right)$ \\
\hline $50 \%$ & $16,33 \mathrm{a}$ & $4,40 \mathrm{a}$ & $38,33 \mathrm{a}$ & $1,53 \mathrm{a}$ \\
$70 \%$ & $15,73 \mathrm{a}$ & $4,06 \mathrm{a}$ & $38,86 \mathrm{a}$ & $1,40 \mathrm{a}$ \\
Sol & $12,53 \mathrm{~b}$ & $4,06 \mathrm{a}$ & $36,86 \mathrm{~b}$ & $1,60 \mathrm{a}$ \\
\hline CV \% & 8,26 & 2,77 & 11,28 & 26,1 \\
\hline
\end{tabular}

Em que: médias seguidas pela mesma letra nas colunas não diferem entre si pelo teste de Tukey a $5 \%$ de probabilidade 
a)

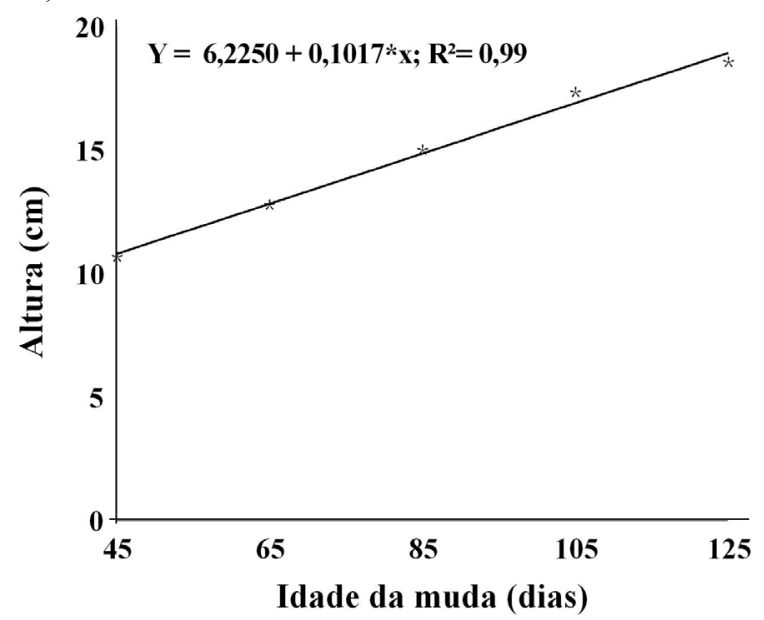

b)

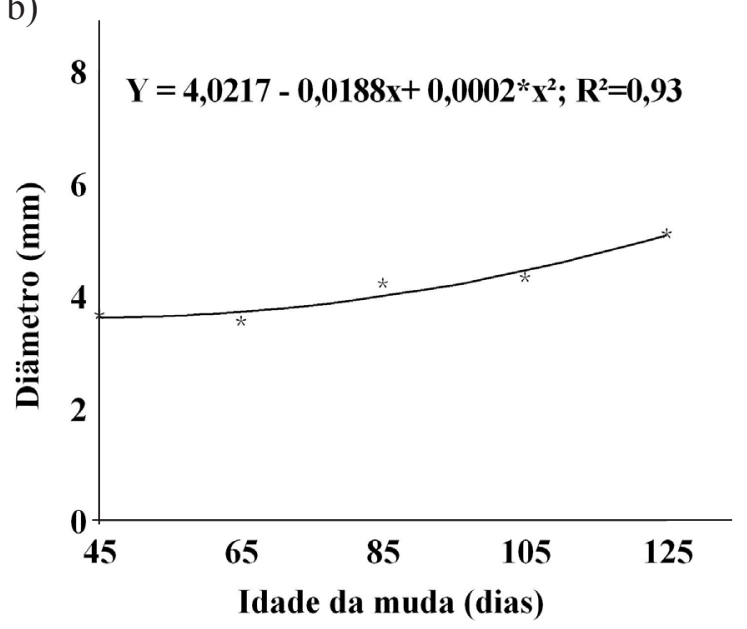

FIGURA 1: Altura de mudas e diâmetro do coleto de Dipteryx alata em função da idade das mudas. FIGURE 1: Height and diameter of collect seedlings of Dipteryx alata in function of seedling ages.

de mudas de castanha-do-maranhão [Bombacopsis glabra (Pasq.) A. Robyns] submetidas a níveis de sombreamento de 0,30 e $50 \%$, e de sangra-d'água (Croton urucurana Baill) a $50 \%$ de sombreamento, também constataram maior altura em mudas sombreadas e diâmetro de coleto indiferente aos níveis de luz. Silva e Leite (2002) avaliando o efeito do sombreamento de 0,30 e $50 \%$ e da torta de filtro na produção de mudas de cedro (Cedrella fissilis Veloso), também não verificaram diferença no diâmetro de colo aos 110 dias após a semeadura.

Os teores de clorofila também foram maiores em mudas sombreadas (Tabela 2), e mantiveram um comportamento quadrático no decorrer das avaliações com ponto de mínimo aos 85 dias (Figura 2a). Esse aumento dos teores de clorofila, especialmente de clorofila $b$, nas folhas aumenta a capacidade de absorção de luz, de diferentes comprimentos de onda nos picos da fotossíntese, tal como a luz na faixa do azul, presente em grande quantidade em locais sombreados (TAIZ e ZEIGER, 2004). Em intensidades elevadas de radiação, as moléculas de clorofila são suscetíveis à foto-oxidação e o equilíbrio é atingido somente em níveis mais baixos de radiação. Portanto, as folhas das plantas de ambientes sombreados, dependendo da espécie, apresentam maiores teores de clorofila do que as folhas que são crescidas a pleno sol (KRAMER e KOZLOWSKI, 1979). Não houve influência do sombreamento sobre a transpiração (Tabela 2), que apresentou pequeno declínio até os 105 DIM, elevando-se em seguida (Figura 2b).

Observa-se na literatura que o comportamento transpiratório de mudas em diferentes disponibilidades de luz é variável. Resultados semelhantes aos observados para baru também foram observados por Lima Junior et al. (2006), que estudando os aspectos fisioanatômicos de plantas jovens de Cupania vernalis Camb. submetidas a diferentes níveis de sombreamento de $0,30,50$ e $70 \%$, não verificaram diferenças na transpiração. Entretanto, Welander e Otosson (2000) observaram para Quercus robur maiores taxas de transpiração com o aumento da irradiância.

A taxa fotossintética e a condutância estomática foram maiores nas plantas a pleno sol (Figura 3a e 3b), seguida das plântulas sob $50 \%$ de sombreamento. Semelhante à taxa de transpiração, a condutância estomática reduziu até os 85 DIM elevando-se em seguida, entretanto, esse comportamento foi contrário ao observado para a taxa fotossintética, sugerindo que outros fatores, além da condutância estomática, podem afetar a taxa fotossintética das folhas de baru.

A queda da fotossíntese também pode ser atribuída à fotoinibição (DIAS e MARENCO, 2006). Alvarenga et al. (2003) também verificaram em Croton urucurana Baill que as maiores taxas fotossintéticas ocorreram em plantas cultivadas em níveis mais elevados de irradiância.

Conforme a literatura, a capacidade fotossintética é uma característica intrínseca de cada espécie vegetal, sendo que as trocas gasosas podem mudar durante o ciclo do desenvolvimento do indivíduo e dependem do curso anual e até mesmo do curso diário das flutuações ambientais como luz e temperatura, dentre outros, em torno do vegetal (LARCHER, 2000). 
a)

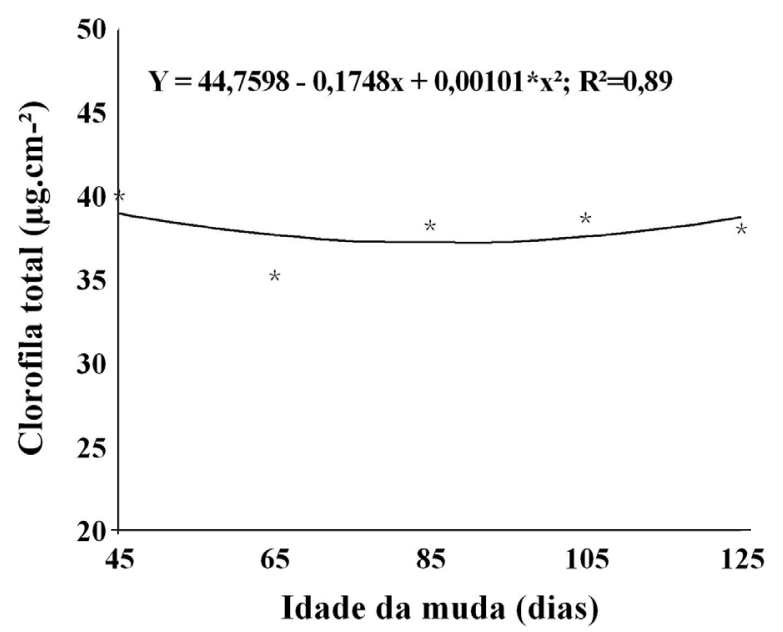

b)

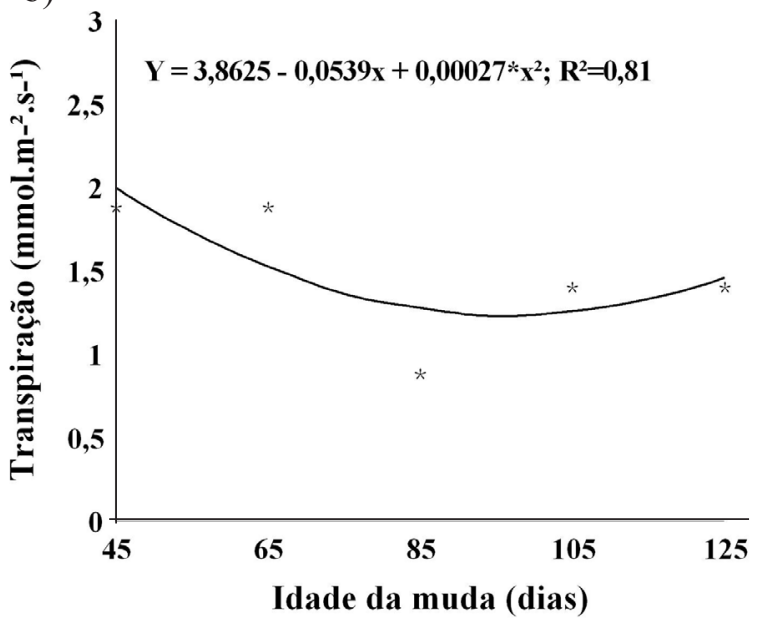

FIGURA 2: Clorofila total e transpiração de Dipteryx alata em função da idade das mudas.

FIGURE 2: Total chlorophyll and transpiration of Dipteryx alata in function of seedling ages.

a)

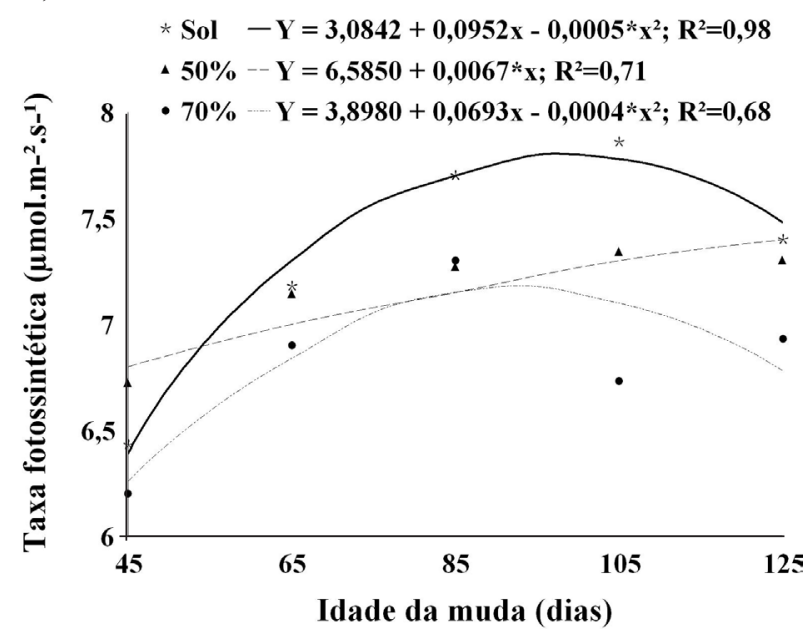

b)

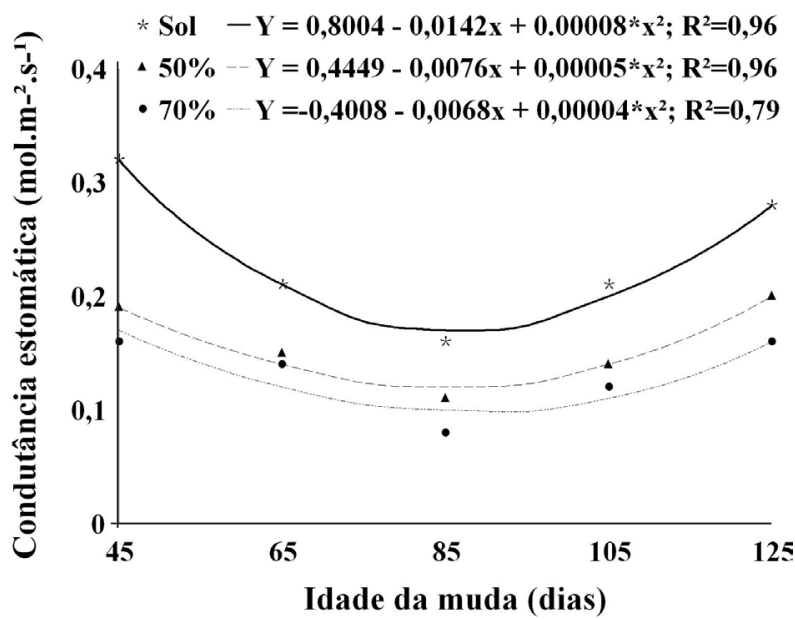

FIGURA 3: Taxa fotossintética e condutância estomática de Dipteryx alata em diferentes idades. FIGURE 3: Photosynthetic rate and stomatal conductance of Dipteryx alata in different ages.

Tendência semelhante em relação à condutância estomática também foi observada para as mudas de C. vernalis (LIMA JUNIOR et al., 2006), para Carapa guianensis (COSTA e MARRENCO, 2007) e para Eucalyptus citriodora (Hook) (FERREIRA et al., 1999), as quais também apresentam os maiores valores de condutância estomática quando a radiação solar é máxima e o potencial hídrico da folha ainda não atingiu os valores mínimos passíveis de induzir o fechamento estomático (OREN et al., 1999).

A área foliar aos 125 DIM manteve-se maior e não variou entre os níveis de sombreamento, entretanto, aos 45 DIM as mudas sob $0 \%$ de sombreamento apresentaram menor área foliar. Dentre as mudas sombreadas, as cultivadas sob $50 \%$ de sombreamento apresentaram maiores valores (Tabela 3 ).

A maior área foliar observada sob sombreamento está relacionada a um recurso morfológico para maximizar a interceptação dos raios solares. Resultados semelhantes também foram observados por Silva et al. (2004) para mudas de faveira (Clitoria fairchildinana R. A. Howard) cultivadas sob diferentes níveis de sombreamentos $(0,50$ e $70 \%)$, quando apresentaram maior área foliar 
TABELA 3: Área foliar (AF), Comprimento de Raiz (CR), Massa Fresca (MF) e Massa Seca (MS) de mudas de Dipteryx alata aos 45 e 125 dias de idade em função dos níveis de radiação.

TABLE 3: Leaf area (LA), length of root (LR), fresh (FM) and dry mass (DM) of Dipteryx alata of 45 and 125 days of age in function of levels shadings.

\begin{tabular}{|c|c|c|c|c|c|}
\hline Sombreamento & $\begin{array}{c}\text { Idade da muda } \\
\text { DIM }\end{array}$ & $\begin{array}{c}\mathrm{AF} \\
\left(\mathrm{cm}^{2}\right)\end{array}$ & $\begin{array}{l}\mathrm{CR} \\
(\mathrm{cm})\end{array}$ & $\begin{array}{l}\text { MF } \\
(\mathrm{g})\end{array}$ & $\begin{array}{l}\text { MS } \\
(\mathrm{g})\end{array}$ \\
\hline \multirow{2}{*}{$50 \%$} & 45 & $174,35 \mathrm{~b} \mathrm{~A}$ & 15,13 a A & $5,13 \mathrm{~b} \mathrm{~A}$ & $1,59 \mathrm{~b} \mathrm{~A}$ \\
\hline & 125 & 251,00 a A & 15,53 a A & 10,26 a A & 3,36 a A \\
\hline \multirow{2}{*}{$70 \%$} & 45 & $131,33 \mathrm{a} \mathrm{AB}$ & 13,76 a $\mathrm{AB}$ & $3,96 \mathrm{~b} \mathrm{~A}$ & $1,13 \mathrm{~b} \mathrm{~A}$ \\
\hline & 125 & $189,33 \mathrm{a} \mathrm{A}$ & 14,33 a A & 9,16 a $\mathrm{AB}$ & 3,06 a $\mathrm{AB}$ \\
\hline \multirow{2}{*}{ Sol } & 45 & 71,68 b B & 10,93 a B & $3,66 \mathrm{~b} \mathrm{~A}$ & $0,96 \mathrm{~b} \mathrm{~A}$ \\
\hline & 125 & $154,00 \mathrm{a} \mathrm{A}$ & 13,83 a A & 7,86 a $\mathrm{B}$ & 2,40 a B \\
\hline $\mathrm{CV} \%$ & & 21,38 & 13,99 & 15,34 & 18,79 \\
\hline
\end{tabular}

Em que: médias seguidas pela mesma letra minúscula nas colunas não diferem significativamente nos tratamentos entre idades distintas e com letra maiúscula não diferem significativamente entre si nos tratamentos para uma mesma idade pelo teste de Tukey a $5 \%$ de probabilidade.

em plantas submetidas a $50 \%$ de sombreamento e por Alvarenga et al. (2003) para Croton urucurana Baill., onde as maiores áreas ocorreram sob $70 \%$ de sombreamento.

A área foliar pode ser considerada um índice de produtividade, dada a importância dos órgãos fotossintetizantes na produção biológica (SCALON et al., 2003) e, em espécies tolerantes ao sombreamento, ela tende a ser aumentada em condições de baixa disponibilidade de radiação solar, ao passo que em espécies heliófitas a área foliar tende a aumentar com o aumento da radiação (DALE, 1988). Baseando-se nessas informações, as mudas de baru, nessa fase inicial de crescimento, podem ser consideradas tolerantes ao sombreamento, uma vez que a área foliar não aumentou com a maior luminosidade.

O comprimento da raiz foi maior sob sombreamento (50 e $70 \%$ ) embora, no mesmo nível de sombreamento não tenha variado entre as idades das mudas (Tabela 3). A explicação para o fato do crescimento do sistema radicular, ao final das avaliações, não apresentar diferença significativa das avaliações anteriores pode ser uma possível limitação causada pela embalagem onde as mudas se encontravam. Fonseca et al. (2006) trabalhando com plântulas de Pseudopiptadenia psilostachya (DC.) G. P. Lewis e M. P. Lima, submetidas a diferentes níveis de luminosidade $(0,30,50$ e $70 \%$ de sombra), também não observaram diferença no comprimento das raízes ao final do experimento.
As maiores massas fresca e seca das mudas aos 125 DIM foram observadas quando submetidas ao sombreamento de $50 \%$, comparado aos demais tratamentos. Resultados semelhantes foram também observados por Scalon et al. (2006) para mudas de sombreiro (Clitoria fairchildiana), por Rego e Possamai (2006) para mudas de jequitibá-rosa sob $34,44,64$ e $70 \%$ de radiação fotossinteticamente ativa comparado a pleno sol e por Carvalho et al. (2006) para licuri (Syagrus coronata (Mart.) Becc.) submetidas a $30 \%$ de luz. Segundo Kitao et al. (2000), a exposição prolongada a altas irradiâncias pode ser prejudicial ao crescimento de plântulas, por absorverem mais fótons de luz do que podem utilizar, podendo ter como consequência a fotoinibição ou, mesmo, a morte.

\section{CONCLUSÕES}

A emergência das plântulas de baru é indiferente ao sombreamento, entretanto, o maior crescimento inicial é observado quando as mudas são mantidas até os 125 dias de idade sob $50 \%$ de sombreamento.

\section{AGRADECIMENTOS}

Ao Conselho Nacional de Desenvolvimento Científico e Tecnológico (CNPq) pelas bolsas concedidas e à FUNDECT pelo auxílio financeiro. 


\section{REFERÊNCIAS BIBLIOGRÁFICAS}

AGUIAR, L. M. de S. et al. A diversidade biológica do Cerrado. In: AGUIAR, L. M. de; CAMARGO, A. J. A. (Org.). Cerrado: ecologia e caracterização. Planaltina: Embrapa Cerrados; Brasília: Embrapa Informação Tecnológica, 2004. p.17-40.

ALVARENGA, A. A. et al. Effects of different light leveld on the initial growth and phothosynthesis of Croton urucurana Baill. In. southeastern Brazil. Revista Árvore, Viçosa, v. 27, n. 1, p. 53-57, 2003. ATROCH, E. M. A. C. et al. Crescimento, teor de clorofila, distribuição de biomassa e características anatômicas de plantas jovens de Bauhinia forficata Link submetidos à diferentes condições de sombreamento. Ciência e Agrotecnologia, Lavras, v. 25, n. 4, p. 853-862, 2001.

BARBOSA, L. M. et al. Recuperação florestal com espécies nativas no Estado de São Paulo: pesquisas apontam mudanças necessárias. Florestal Estatístico, v. 6, p. 28-34, 2003.

CAMPOS, M. A. A.; UCHIDA, T. Influência do sombreamento no crescimento de mudas de três espécies amazônicas. Pesquisa Agropecuária Brasileira, Brasília, v. 37, n. 3, p.281-288, mar. 2002.

CARVALHO, N. O. S. et al. Crescimento inicial de plantas de licuri (Syagrus coronata (Mart.) Becc.) em diferentes níveis de luminosidade. Revista Árvore, Viçosa, v. 30 n. 3, 2006.

CORRÊA, G. C.; ROCHA, M. R.; NAVES, R. V. Germinação de sementes e emergência de plântulas de baru (Dipteryx alata Vog.) nos cerrados do estado de Goiás. Pesquisa Agropecuária Tropical, Goiânia, v. 30, n. 2, p. 17-23, 2000.

COSTA G. F; MARENCO R A. Fotossíntese, condutância estomática e potencial hídrico foliar em árvores jovens de andiroba (Carapa guianensis). Acta Amazonica, Manaus, v. 37, n. 2, p. 229 -234, 2007

DALE, J. E. The control of leaf expansion. Annual Review of Plant Physiology, v. 39, p. 267-295, 1988.

DEMUNER, V. G.; HEBLING, S. A.; DAGUSTINHO, D. M. Efeito do sombreamento no crescimento inicial de Gallesia integrifolia(Spreng) Harms. Revista do Museu de Biologia Mello Leitão, v. 17, p. 45-55, 2004.

DIAS, D. P.; MARENCO, R. A. Photoinhibition of photosynthesis in Minquartia guianensis and Swietenia macrophylla inferred by monitoring the initial fluorescence. Photosynthetica, v. 44, n. 2, p.
235-240, 2006.

DUZ, S. R. et al. Crescimento inicial de três espécies arbóreas da Floresta Atlântica em resposta à variação na quantidade de luz. Revista Brasileira de Botânica, São Paulo, v. 27, n. 3, p. 587-596, 2004.

FERREIRA, C.A.G.; DAVIDE,A.C.; CARVALHO, L. R. Relações hídricas em mudas de Eucalyptus citriodora Hook., em tubetes, aclimatadas por tratamentos hídricos. Cerne, Lavras, v. 5, n. 2, p. 95-104, 1999.

FONSECA, C. E. L da et al. Recuperação da vegetação de matas de galeria: estudos de caso no Distrito Federal e entorno. In: RIBEIRO, J. F.; FONSECA, C. E. L. da; SOUZA-SILVA, J. C. (Ed.). Caracterização e recuperação de matas de galeria. Planaltina: Embrapa Cerrados. 2001. p.815-870. FONSECA, M. G.; LEÃO, N. V. M.; SANTOS, F. A. M. Germinação de sementes e crescimento inicial de plântulas de Pseudopiptadenia psilostachya (DC.) G.P.Lewis \& M.P.Lima (Leguminosae) em diferentes ambientes de luz. Revista Árvore, Viçosa, v. 30, n. 6, p. 885891, 2006.

GONÇALVES, F. G.; GOMES, S. da S.; GUILHERME, A. L. Efeito da luz na germinação de sementes de Guatteria gomeziana (Unonopsis lindmanii R. E. FR.). Revista Científica Eletrônica De Engenharia Florestal, Garça, n. 08, 2006.

KITAJIMA K. Ecophysiology of tropical tree seedlings. In: MULKEY S. S.; CHAZDON R. L.; SMITH A. P. (Eds). Tropical forest plant ecophysiology. New York: Chapman \& Hall, p. 559-597, 1996.

KITAO, M. et al. Susceptibility to photoinhibition of three deciduous broadleaf tree species with different successional traits raised under various light regimes. Plant, Cell and Environment, n. 23, p.81-89, 2000.

KLINK, C. A.; MACHADO, R. B. A conservação do Cerrado brasileiro. Megadiversidade, v,1, p.147-155, 2005

KRAMER, T; KOZLOWSKI, T. T. Physiology of woody plants. New York: Academic Press. (1979) LARCHER, W. Ecofisiologia Vegetal. São Carlos, RIMA. São Paulo. 2000. 529 p.

LIMA JUNIOR, E. C. et al. Aspectos fisioanatômicos de plantas jovens de Cupania vernalis Camb. submetidas a diferentes níveis de sombreamento. Revista Árvore, Viçosa, v. 30, n. 1, p.33-41, 2006. MACEDO, J. F. As plantas oleaginosas do cerrado de Minas Gerais. Informe Agropecuário, Belo 
Horizonte, v. 16, n. 173, p. 21-7, 1992.

MARENCO, R. A.; LOPES, N. F. Fisiologia Vegetal: Fotossíntese, respiração, relações hídricas e nutrição mineral. Viçosa: UFV, 2005. 451 p. MATO GROSSO DO SUL. Atlas Multireferencial. Campo Grande: Secretaria de Planejamento e Coordenação Geral, 1990.

MORAIS NETO, S. P. et al. Crescimento de mudas de algumas espécies arbóreas que ocorrem na mata atlântica em função do nível de luminosidade. Revista Árvore, Viçosa, v. 24, n. 1, p. 35-45, 2000. OREN, R. et al. Survey and synthesis of intraand interspecific variation in stomatal sensitivity to vapour pressure deficit. Plant, Cell and Environment, v. 22, n. 12, p. 1515-1526, 1999.

POPINIGIS, F. Fisiologia da semente. Brasília: Agiplan, 1985. 289 p.

PORTELA, R. C. Q.; SILVA, I. L.; PINÃRODRIGUES, F. C. M. Crescimento inicial de mudas de Clitoria fairchildiana Howard e Peltophorum dubium (Sprenge) Taub em diferentes condições de sombreamento. Ciência Florestal, Santa Maria, v. 11, n. 2, p. 163-170, 2001.

REGO, G. M.; POSSAMAI, E. Efeito do Sombreamento sobre o Teor de Clorofila e Crescimento Inicial do Jequitibá-rosa. Boletim de Pesquisa Florestal. Colombo, v. 53, p. 179-194, 2006.

SANO, E. E. et al. Mapeamento semidetalhado do uso da terra do Bioma Cerrado. Pesquisa Agropecuária Brasileira, Brasília, v. 43, n. 1, p. 153-156, 2008.

SANO, E. E.; JESUS, E. T.; BEZERRA, H. S. Uso de um sistema de informações geográficas para quantificação de áreas remanescentes do Cerrado. Planaltina: Embrapa Cerrados, 2001. 4 p. (Embrapa Cerrados. Comunicado Técnico, 62).

SANO, S. M., RIBEIRO, J. F., BRITO, M. A. De. Baru: biologia e uso - Planaltina: Embrapa Cerrados 2004.

SANTARELLI, E. G. Produção de mudas de espécies nativas. In: RODRIGUES, R. R.; LEITÃO FILHO, H. F. (Ed.). Matas ciliares: conservação e recuperação. 3. ed. São Paulo: Edusp/Fapesp, 2004. p. 313-318.

SCALON, S. P. Q. et al. Crescimento inicial de mudas de Bombacopsis glabra (Pasq.) A. Robyns sob condição de sombreamento. Revista Árvore, Viçosa, v. 27, n. 6, p. 753-758, 2003.

SCALON, S. P. Q. et al. Crescimento inicial de mudas de sangra-d'água (Croton urucurana Baill.) sob sombreamento e aplicação de de giberelina. Revista Brasileira de Plantas Medicinais, v. 10, n. 3, p. 61-6, 2008

SCALON, S. P. Q. et al. Desenvolvimento de mudas de Aroeira (Schinus terebinthifolius) e sombreiro (Clitoria fairchildiana) sob condições de sombreamento. Ciência e Agrotecnologia, Lavras, v. 30, n. 1, p. 166-169, 2006.

SILVA, A. C. ; LEITE, G. F. Efeito do sombreamento e da torta de filtro na produção de mudas de cedro (Cedrella fissilis Veloso). In: SIMPÓSIO NACIONAL DE RECUPERAÇÃO DE ÁREAS DEGRADADAS - ÁGUAS E BIODIVERSIDADE, 5., 2002, Belo Horizonte. Anais... Belo Horizonte, 2002. v. 1. p. 225-228.

SILVA, A. K. da ; EGITO, M. do. Rede de comercialização solidária de agricultores familiares e extrativistas do cerrado: um novo protagonismo social. Agriculturas - v. 2 - n. 2, jun. 2005.

SILVA, B. M. S.; CESARINO, F.; PANTOJA, T. F. Efeito de diferentes níveis de radiação sobre o crescimento inicial de Clitoria fairchildinana R. A. Howard. In: REUNIÃO ANUAL DO INSTITUTO BIOLÓGICO, 17., 2004, São Paulo. Anais... São Paulo, 2004. v. 71, p. 1-749.

SILVA, C.V. et al. Fracionamento e germinação de sementes de uvaia (Eugenia pyriformis Cambess. Myrtaceae). Revista Brasileira de Botânica, São Paulo, v. 26, p. 213-221, 2003.

TAIZ. L.; ZEIGER, E. Fisiologia vegetal. Porto Alegre: Artmed, 2004. $719 \mathrm{p}$.

TURNER, I.M. The ecology of trees in the tropical rainforest. Cambridge: Cambridge University Press, 2001. 298 p.

WELANDER, N. T.; OTOSSON B. The influence of low light, droughtand fertilization on transpiration and growt in young seedllings of Quercus robur. Forest ecology and Management, v. 127, n. 1/3, p. 139-151, 2000.

ZAMITH, L. R.; SCARANO, F. R. Produção de mudas de espécies das Restingas do município do Rio de Janeiro, RJ, Brasil. Acta Botanica Brasilica, São Paulo, v. 18, p. 161-176, 2004. 